\title{
Itinéraires Itinéraires
}

Littérature, textes, cultures

2019-2 et $3 \mid 2019$

Corps masculins et nation : textes, images, représentations

\section{Du caudillo à l'homme au foyer : la déconstruction de la virilité dans le roman El Conspirador (1892) de Mercedes Cabello de Carbonera}

From Caudillo to House Husband: The Deconstruction of Virility in the Novel El Conspirador (1892) of Mercedes Cabello de Carbonera

\section{Sarah Porcheron}

\section{(2) OpenEdition}

Journals

\section{Édition électronique}

URL : http://journals.openedition.org/itineraires/6404

DOI : $10.4000 /$ itineraires.6404

ISSN : 2427-920X

Éditeur

Pléiade

Référence électronique

Sarah Porcheron, « Du caudillo à I'homme au foyer : la déconstruction de la virilité dans le roman El Conspirador (1892) de Mercedes Cabello de Carbonera », Itinéraires [En ligne], 2019-2 et 3 | 2019, mis en ligne le 11 décembre 2019, consulté le 15 décembre 2019. URL : http://journals.openedition.org/ itineraires/6404; DOI : 10.4000/itineraires.6404

Ce document a été généré automatiquement le 15 décembre 2019.

\section{$\theta \Theta \Theta \Theta$}

Itinéraires est mis à disposition selon les termes de la licence Creative Commons Attribution - Pas d'Utilisation Commerciale - Pas de Modification 4.0 International. 


\title{
Du caudillo à l'homme au foyer : la déconstruction de la virilité dans le roman El Conspirador (1892) de Mercedes Cabello de Carbonera
}

\author{
From Caudillo to House Husband: The Deconstruction of Virility in the Novel El \\ Conspirador (1892) of Mercedes Cabello de Carbonera
}

Sarah Porcheron

\section{Introduction}

1 Le XIX ${ }^{e}$ siècle constitue en Amérique latine un tournant politique, économique et socioculturel en raison des mouvements d'indépendance qui l'ont traversé, donnant naissance à une pluralité de nations. Dans L'imaginaire national. Réflexions sur l'origine et l'essor du nationalisme, Benedict Anderson soutient l'idée que la nation est commune à toutes les sociétés car elle définit et caractérise les individus qui la peuplent. Pour Anderson, la nation repose ainsi sur quatre fondements essentiels : elle est imaginée car relève d'une représentation abstraite où les individus partagent un sentiment commun d'appartenance ; elle se limite à un territoire ; elle est souveraine, considérée comme libre et constitue une communauté fondée sur le principe de "camaraderie " entre individus (Anderson [1983] 1996: 20). Dans le cadre de cet article, ce concept de «nation" est particulièrement remarquable car il permet d'appréhender le phénomène de la construction de l'identité collective des individus, c'est-à-dire le processus de formation de l'identité nationale. Dans le contexte de pays nouvellement indépendants de la domination espagnole, c'est une réflexion qui va également animer les écrivains latino-américains à travers la littérature tout au long du XIX ${ }^{e}$ siècle.

2 Au sein de ces jeunes nations, les intellectuels ont conçu la littérature comme le vecteur privilégié de la construction de l'imaginaire national. Pour Julio Ramos (1989: 
62), les sociétés latino-américaines récemment émancipées concevaient l'écriture comme une "práctica racionalizadora " (" pratique rationnalisante »). Autrement dit, le fait de "rationnaliser " l'écriture signifiait, pour les intellectuels et les dirigeants politiques latino-américains, élaborer des textes qui puissent donner du sens et de l'ordre aux événements qui étaient en train de se dérouler. Lors des guerres d'indépendance, la narration des actions militaires s'est particulièrement développée. Les héros de l'indépendance ont écrit des lettres, des proclamations et des discours dont les principales thématiques étaient la défense des idéaux de liberté et de justice. $\mathrm{Au}$ cours de la première étape d'émancipation de la domination espagnole, la fiction était absente de ces textes. Ce n'est qu'une fois l'indépendance acquise, que les intellectuels latino-américains ont utilisé l'œuvre fictionnelle pour imaginer et promouvoir leur propre idéal national au sein de la population. L'émancipation culturelle des sociétés américaines et la consolidation de l'État constituaient les principales priorités de la période de postindépendance (Licón $n$. d. : 1-3). Les lettrés latino-américains étaient convaincus qu'à partir de l'écriture il était possible d'éduquer les masses, de remplir le vide de presque trois siècles de colonisation et donc de restructurer la société.

Pour l'écrivain/homme d'État, il n'existait pas de distinction précise épistémologique entre l'art et la science, le texte narratif et les faits, et par conséquent, entre les projections idéales et les projets réels ${ }^{1}$. (Sommer [1991] 2004 :

24)

Force est de constater que les liens entre littérature et projet national sont étroits au $\mathrm{XIX}^{\mathrm{e}}$ siècle en Amérique latine. Par ailleurs, comme le fait remarquer Doris Sommer, les figures de l'homme politique et de l'homme de lettres se confondaient souvent, comme le prouve le fait que de nombreux écrivains ont également assumé d'importants postes à responsabilités politiques.

D'un point de vue littéraire, le $\mathrm{XIX}^{\mathrm{e}}$ siècle est donc celui de l'essor des essais et des poésies patriotiques. C'est également à ce moment-là que se développe le costumbrismo, en tant que mouvement artistique et littéraire dérivé du romantisme européen. Notons qu'en Amérique latine, il est intimement lié à l'idéal de construction d'une identité propre après l'indépendance. La représentation des particularités culturelles et géographiques latino-américaines entrait dans l'objectif de récupération d'une identité collective, attitude proche du nationalisme et du régionalisme. Quant au roman, objet de notre réflexion, en raison de son caractère extensif et de la représentation de personnages inspirés de la réalité, il devient le support littéraire privilégié pour configurer les nouveaux acteurs nationaux (Anderson [1983] 1996: 24). Aussi bien aux États-Unis qu'au sein des jeunes républiques latino-américaines, la construction nationale et le roman se sont développés simultanément. Les intellectuels latinoaméricains ont vu dans la production de romans nationaux ${ }^{2}$ un puissant moyen de promouvoir de nouveaux idéaux liés à la liberté, à la justice et au triomphe républicain. $\mathrm{Au}$ Pérou, où ce genre littéraire était peu ou pas assez exploité, le premier roman, intitulé El inventario de Julián Manuel Del Portillo (1818-1862), n'a été publié qu'en 1842 et il faudra attendre vingt-cinq ans pour voir la parution du premier roman féminin, Un amor desgraciado (1867) de Carolina Freyre de Jaimes (1844-1916). Entre 1870 et 1879, on compte seulement vingt-six romans, dont deux, uniquement, écrits par des femmes ${ }^{3}$. Néanmoins, le genre s'est progressivement imposé comme celui de la modernité, au Pérou et dans toute l'Amérique latine. 
4 Les guerres de pouvoir et la militarisation des nations latino-américaines après la période indépendantiste ont orienté la formation des identités nationales (Peluffo et Sánchez Prado 2010 : 8). Dans l'Amérique latine du XIX siècle, l'idée de la masculinité virile se confond avec une forme d'héroïsme belliqueux. L'exacerbation de l'agressivité visait à définir les codes de l'apparence masculine et à la différencier de la féminine, ainsi que des ennemis potentiels en termes de force (González Stephan 2010 : 37). Il s'agissait d'une réponse aux faiblesses «féminisantes » de la masculinité sentimentale véhiculée par les romans issus du romantisme (Peluffo et Sánchez Pardo 2010: 7). Notons que les sociétés du $\mathrm{xIX}^{\mathrm{e}}$ siècle se caractérisaient dans leur ensemble par l'adoption d'une idéologie patriarcale où les activités entre hommes et femmes se trouvaient radicalement différenciées en fonction du genre. Le « masculin » incarnait le genre hégémonique du pouvoir, de la raison et de la sphère publique. En revanche, le "féminin " s'assimilait à la soumission, la reproduction biologique, la sensibilité et l'espace domestique. On retrouve ce système de pensée dans une grande majorité de romans latino-américains du XIX ${ }^{e}$ siècle. Si l'on reprend le cas des romans nationaux, le personnage masculin incarnait un patriote vertueux dans la sphère publique et un époux idéal dans le domaine privé. Le personnage féminin s'inscrivait avant tout dans les valeurs de la famille patriarcale : pudeur, soumission à l'autorité du mari, loyauté et abnégation.

5 Au Pérou, après les conflits générés par les guerres d'indépendance, s'ajouta la défaite de la guerre du Pacifique (1879-1883), un événement qui accentua les inégalités sociales et la fragilité institutionnelle. La déroute de la guerre du Pacifique provoqua l'opposition idéologique et esthétique de deux groupes littéraires incarnés par l'écrivain romantique Ricardo Palma (1833-1919) et l'essayiste anarchiste Manuel González Prada (1844-1918). Les romantiques produisaient une littérature certes patriotique mais refusaient de prendre part aux discussions politiques. Dans les ouvrages de la génération des romantiques péruviens, également surnommés par euxmêmes «los bohemios » («les bohèmes »), les questions politiques étaient éludées pour faire la part belle au sentiment patriotique et au quotidien de la vie domestique de l'aristocratie liménienne à l'époque du guano ${ }^{4}$. Pour les romantiques, le roman répondait à un objectif esthétique et moral: moraliser la société par le biais de l'idéalisation des sentiments et fonder un nouveau genre littéraire au Pérou. Ces écrivains glorifiaient la patrie mais se concevaient, en revanche, comme des agents culturels «neutres» au regard des luttes politiques. Selon eux, à l'image du foyer, l'espace littéraire incarnait une sorte de "refuge», ordonné et réconfortant, aux antipodes d'une réalité qu'ils considéraient comme décevante et chaotique.

6 Après la défaite péruvienne, l'anarchiste Manuel González Prada prit la tête de l'association culturelle Círculo Literario où il développa une nouvelle conception de la littérature à l'opposé de la vision apolitique de la génération des romantiques. D'après Prada, la littérature devait constituer un organe critique par rapport à l'État et analyser les dérives sociales et politiques de la société afin d'y remédier. Tandis que durant la seconde moitié du XIX $x^{e}$ siècle péruvien les caudillos ${ }^{5}$ se succédèrent à la tête du pays, dans les discours des intellectuels nationaux, la figure masculine du soldat belliqueux se construisit en tant que sujet national idéal (Peluffo 2004: 104). Le texte Nuestros indios ("Nos indiens») de González Prada, publié en 1904, est un exemple caractéristique de cet imaginaire national masculin. Prada défend l'idée selon laquelle l'intégration de l'Indien dans la société péruvienne n'est possible qu'à condition de le 
"viriliser» en lui inculquant un sentiment de haine envers l'ancien envahisseur chilien :

La condition de l'indigène peut s'améliorer de deux façons: ou le cœur des oppresseurs ressent une extrême pitié pour la reconnaissance du droit des opprimés, ou bien l'état d'âme des opprimés acquiert la virilité nécessaire pour donner une leçon à ses oppresseurs. Si au lieu de gaspiller tout son argent dans l'alcool et les fêtes, l'Indien en profitait pour acheter des fusils et des munitions, s'il cachait une arme dans le recoin de sa baraque ou dans le trou d'un rocher, alors il changerait sa condition et ferait respecter sa propriété et sa propre vie. À la violence répondrait la violence, donnant ainsi une bonne leçon au patron qui lui confisque ses laines, au soldat que l'on enrôle au nom du gouvernement, au montanero ${ }^{6}$ qui lui vole son bétail et ses bêtes de somme. Cessons de prôner l'humilité et la résignation de l'Indien et encourageons à la place l'orgueil et la rébellion?7. (González Prada 1908 : 343)

L'expression "À la violence répondrait la violence ", de même que le champ lexical de l'agressivité comme mode d'intégration de l'Indien est le signe de l'exacerbation d'un type de masculinité virile au sein de la population.

7 À l'égard des femmes, la démocratisation de la politique et des institutions au XIX ${ }^{e}$ siècle en Amérique latine n'a pas eu pour effet leur insertion dans la sphère publique mais, au contraire, leur exclusion. La diffusion d'idéologies égalitaires issues de la modernité aurait en effet pu constituer une "porte d'entrée" pour les femmes dans la vie publique, mais leur intégration potentielle représentait également un danger pour les institutions républicaines détenues par le patriarcat. L'amplification de l'emprise masculine sur les femmes s'est réalisée durant la période de modernisation nationale par leur confinement à l'espace domestique. Ainsi, les rôles sociaux attribués aux femmes étaient limités aux fonctions maternelles et domestiques. Cependant, elles n'étaient pas complètement exclues des sphères de pouvoir, grâce à l'essor de la figure de la femme de lettres qui organisait des veladas literarias ("réunions littéraires ») dans son propre salon (Pratt 1999: 47-49). Ces réunions culturelles et artistiques mixtes existaient depuis la colonisation espagnole où les femmes pouvaient venir accompagnées de leurs enfants et de leurs époux afin de débattre sur des sujets liés à l'art. Avant la guerre du Pacifique, cette tradition a été remise au goût du jour par l'écrivaine argentine Juana Manuela Gorriti (1818-1892), au regard de l'absence de réunions littéraires ouvertes aux deux sexes. Bien que les femmes fussent autorisées à exposer leurs écrits dans ces réunions culturelles, les veladas de Gorriti masquaient ou éclipsaient le contenu politique explicite des écrits des participantes. En revanche, après la guerre du Pacifique, les veladas furent reprises par l'écrivaine péruvienne Clorinda Matto de Turner (1852-1909) qui leur donna un contenu beaucoup plus politisé et social car l'objectif de ces réunions était désormais d'œuvrer à la reconstruction nationale par la littérature et les arts. Le phénomène des veladas d'avant et d'aprèsguerre est particulièrement intéressant car il a permis aux femmes de pénétrer dans un milieu intellectuel jusqu'alors grandement dominé par les hommes et d'obtenir une notoriété publique, en particulier grâce à la présence de la presse dans ces réunions. Suite à ces veladas est apparue au Pérou la première génération de femmes de lettres qui a produit une série de textes traduisant leur propre conception de la société. Dans un premier temps, elles se tournèrent plutôt vers la poésie, puis vers la publication d'articles de presse, et pour certaines d'entre elles, les essais et le roman. Mercedes Cabello de Carbonera fait partie de cette première génération de femmes de lettres péruviennes et a aussi activement participé aux veladas. Ainsi, lorsqu'elle publia en 1892 
son dernier roman El Conspirador. Autobiografía de un hombre público. Novela político-social, elle représentait déjà une intellectuelle de poids dans le milieu culturel péruvien.

Dans ce roman, elle expose sa propre vision de la classe politique péruvienne pour proposer une conception alternative au modèle hégémonique de masculinité agressive. Elle écrit les mémoires d'un héros fictif, Jorge Bello, censé incarner l'archétype du conspirateur politico-militaire. La narration autodiégétique à la première personne du singulier est rythmée par les différentes étapes de la vie de conspirateur de Bello: adolescent obsédé par l'acquisition de la force physique, caudillo viril, puis putschiste enfermé dans un espace domestique et forcé à vivre aux dépens de sa maîtresse Ofelia Olivas, devenue la nouvelle cheffe du parti politique qu'il avait fondé. À partir de l'expérience personnelle du héros-narrateur Jorge Bello, Mercedes Cabello de Carbonera invite son lecteur à réfléchir de façon globale sur la dégradation de la politique péruvienne. Ainsi, nous analyserons la manière dont le roman met en lumière les conséquences d'un imaginaire national hégémonique qui véhicule un type de masculinité virile et agressive pour mieux le déconstruire. Pour ce faire, notre réflexion se divisera en deux axes. Dans un premier temps, nous examinerons l'écriture du « je » comme un acte confessionnel qui permet la découverte d'une masculinité idéale (puissance physique, pouvoir, initiation sexuelle, etc.) coïncidant avec l'acquisition de la conscience nationale du personnage principal. Puis, nous étudierons le processus de « féminisation » du héros au contact d'un personnage féminin, Ofelia Olivas, qui accède aux plus hautes sphères du pouvoir.

\section{L'écriture du « je » : de l'acquisition de la virilité à la conscience nationale}

9 Le roman El Conspirador constitue une critique acerbe de la vie politique péruvienne à la fin du XIXe siècle. Le sous-titre accrocheur Autobiografía de un hombre público instaure un pacte de lecture qui consiste à renforcer l'illusion du réel des faits racontés. Il ne s'agit pas toutefois d'une autobiographie véritable car l'identité du héros-narrateur Jorge Bello et celle de la romancière Mercedes Cabello de Carbonera diffèrent. Jorge Bello est un personnage masculin fictif, il n'est donc pas véritablement question dans ce cas d'un roman autobiographique puisque ce récit à la première personne ne s'inspire pas de la vie de l'auteur. Dans Le Pacte autobiographique, Philippe Lejeune donne la définition suivante de l'autobiographie : "Récit rétrospectif en prose qu'une personne réelle fait de sa propre existence, lorsqu'elle met l'accent sur sa vie individuelle, en particulier sur l'histoire de sa personnalité " (Lejeune 1974: 14). L'autobiographie implique donc l'identité de l'auteur, du narrateur et du personnage. Cependant, si la forme de narration privilégiée dans El Conspirador est bien celle de l'« écriture de soi ", il s'agit pourtant d'un «je » fictionnel. Dans son étude sur l'« écriture de soi », Jean-Philippe Miraux envisage le recours à la narration par une tierce personne fictive comme une façon pour l'auteur d'avoir une prise de position plus marquée que s'il écrivait en son propre nom. Dans le contexte violent de la guerre, de la soumission ou encore des conflits politiques, comme c'est le cas dans El Conspirador, le "je» fictionnel est finalement un moyen de raconter l'indicible en atténuant les éventuelles remontrances des critiques (Miraux [1996] 2007 : 111). Nous considérons que le dernier roman de Mercedes Cabello de Carbonera relève plus précisément du roman-mémoires, un genre littéraire dérivé de l'autobiographie. Ce dernier terme n'apparaît à aucun moment du 
récit, mis à part dans le sous-titre. En revanche, à plusieurs reprises, le personnage principal Jorge Bello caractérise son propre récit de "mémoires ", qu'il considère à la fois comme un texte personnel par le récit de soi et comme un texte public par la narration du contexte politique de l'époque. Cette dimension collective et individuelle $\mathrm{du}$ récit de Bello est à mettre en parallèle avec la définition que donne René Demoris du genre littéraire des mémoires. Selon lui, ce sont des «relations de faits particuliers pour servir à l'histoire " (Demoris 2002: 70). Bien que les mémoires de Jorge Bello soient en définitive une illusion fictionnelle, la romancière considère que ceux-ci remplissent la même fonction que ceux rédigés par une personne réelle : l'élaboration d'une histoire future. Dans $E l$ Conspirador, dès le début du récit, le héros-narrateur expose au lecteur la principale motivation de l'écriture de ses mémoires : éviter aux générations futures de reproduire ses erreurs de caudillo8.

Je veux publier ces mémoires. Peut-être seront-ils un jour de quelque utilité pour mes contemporains; peut-être pourront-ils servir d'exemple à ceux qui, fascinés par les richesses acquises sans effort, encouragés par les spéculateurs qui rôdent autour des hommes publics et égarés par leurs propres passions, croient comme je le croyais également, que le chemin le plus sûr est celui de la fraude et de la spéculation, parsemé d'embûches et de dangers, et non le grand chemin, lumineux, qui expose à tous les regards et prémunit contre toutes les chutes.

Oui, je publierai ces mémoires, et la confession publique de mes fautes, me rendra peut-être la sérénité que j'ai perdue !.... (El Conspirador : 286).

De même, sa méthode de narration part du récit de soi pour s'étendre à une réflexion commune sur l'ensemble de la nation péruvienne: "J'essaierai de retranscrire les événements les plus importants et les plus marquants de ma vie. L'effort de la mémoire m'occupera à toute heure, et lorsque je n'écrirai pas, je penserai ${ }^{10} »$ (El Conspirador : 6). Pour Jorge Bello, il est donc nécessaire de dévoiler au lecteur son enfance, en passant par son adolescence et l'arrivée à l'âge adulte, afin de comprendre son processus de conversion en caudillo : «J'aurais aimé éviter l'histoire de mes premières années mais je la considère nécessaire pour expliquer les mille anomalies qu'il y a dans ma vie; de même que le côté dramatique que l'on pourra y trouver [... ${ }^{11} »($ El Conspirador : 14). Les termes « anomalies », " abstenir » et " dramatique », pour se référer au premier âge du héros, dénotent une confession à contrecœur. Cette première réticence à montrer ces aspects de sa vie est liée au fait que le jeune Bello était aux antipodes de la masculinité hégémonique véhiculée tout au long de la seconde moitié du XIXe siècle péruvien.

Nous empruntons le terme de "masculinité hégémonique " au concept de Raewyn Connell qui renvoie à la domination des hommes sur les femmes et à l'opinion commune selon laquelle il existerait une masculinité authentique. Ainsi, le "masculin » serait naturellement plus enclin à l'agressivité, au libertinage, à la compétitivité, à occuper la place de chef de famille, à s'élever dans la hiérarchie et à conquérir les sphères du pouvoir politique. Dans ce contexte, le corps symboliserait une machine productrice de différenciation du genre. Or, Connell réfute l'idée selon laquelle le corps des hommes relèverait de l'expression d'une masculinité naturelle. Autrement dit, la masculinité n'est pas une donnée biologique ou innée mais bel et bien une construction sociale et fictionnelle (Connell 2014 : 29-33). Dans El Conspirador, on retrouve cette quête d'un corps masculin puissant et viril, censé incarner le modèle de "masculinité authentique ", à travers la narration des souvenirs de Jorge Bello sur la fragilité de son corps infantile.

Je suis né si faible et si rachitique, que personne ne pensait que je vivrais plus d'une trentaine de jours. 
[...] Lorsque j'eus cinq ans, ma tante (je parlerai d'elle plus tard), se référant à ma fragile constitution physique, avait pour habitude de dire :- Comme le pauvre petit est né à sept mois, c'est normal qu'il soit fragile et malade.

Mon rachitisme, bien loin d'être corrigé par une éducation stimulante et dynamique fut exacerbé par l'excessive cajolerie et la tendresse laxiste de mes oncles et tantes ${ }^{12}$. (El Conspirador : 10)

Le rachitisme de l'enfant est conçu dans cet extrait comme un signe extérieur de la fragilité du corps du héros. Le regard rétrospectif du narrateur oppose alors les marques d'affection reçues pendant l'enfance à l'application d'une éducation stricte qui aurait pu modeler un corps physiquement plus fort. En effet, dans l'imaginaire du jeune Jorge Bello la carrière d'homme politique est indissociable de l'image d'un corps masculin puissant et agressif.

Moi-même, ô combien n'ai-je pas souhaité acquérir la puissance physique qui m'a si souvent fait défaut dans ma vie politique mouvementée, nuisant beaucoup à mes projets et manœuvres d'homme public ! Déjà dans ma carrière militaire, ma petite stature ainsi que ma faible et fragile constitution physique m'ont grandement porté préjudice $^{13}$. (El Conspirador : 11)

L'anxiété exprimée ici par Bello à travers le manque met en évidence le fait que, pour le héros, lorsque le corps masculin ne correspond pas à l'idéal de virilité, il est considéré comme incapable de se défendre (Farges 2014 : 91). La narration de Jorge Bello va donc se concentrer durant la première partie du roman sur le travail physique du jeune homme afin de correspondre à l'idéal hégémonique de l'homme viril (94). Comme le souligne Pierre Bourdieu: "La virilité, entendue comme capacité reproductive, sexuelle et sociale, mais aussi comme aptitude au combat et à l'exercice de la violence (dans la vengeance notamment), est avant tout une charge» (Bourdieu [1998] 2014 : 17). Si dans la société patriarcale, les femmes sont associées à la soumission et à l'abnégation, le complexe d'infériorité du jeune Bello sur son physique fragile démontre que les hommes sont également prisonniers de la représentation genrée dominante. Le privilège du masculin s'avère aussi être un piège qui l'oblige à affirmer sa virilité (74). Dès lors, Bello s'efforce dans ses mémoires de démontrer son évolution physique : il tend de plus en plus à affirmer sa force corporelle et à cacher ses attributs féminins.

Lorsque j'eus quinze ans, j'étais déjà un beau et svelte jeune homme, bien décidé à jouer les hommes mûrs avec des garçons plus vieux que moi, et tout ce rachitisme, que ma tante justifiait par l'horrible et antipathique adjectif prématuré, avait presque totalement disparu. Et même si je conservais ma constitution fragile et nerveuse, je voyais déjà les premiers éclats de l'âge viril se manifester rapidement en moi. Les inflexions aiguës de ma voix commencèrent à s'estomper, comme si en grossissant les cordes étaient devenues rauques et puissantes. [...] [L]e poil viril apparut, dessinant un duvet et noircissant mes joues ${ }^{14}$. (El Conspirador : 40)

L'insistance sur les signes extérieurs de virilité du jeune héros - la barbe, la force physique et l'animosité - suggère que la virilité, est avant tout une notion relationnelle. $\mathrm{Au}$ même titre que l'honneur ou la honte, celle-ci doit être validée «devant » et « pour » les autres hommes qui garantissent l'appartenance au groupe (Bourdieu [1998] 2014 : 77-78). Afin de légitimer sa virilité auprès de ses camarades, Jorge Bello décide d'entrer à l'école militaire, lieu par excellence de l'expression de l'agressivité. Autrement dit, l'agressivité et la violence physique constituent dans El Conspirador les piliers fondateurs de la masculinité en construction (Sohn 2009: 50). Par conséquent, l'école militaire symbolise dans ce roman un espace fondamental de formation dans le processus de construction identitaire du caudillo Bello, car son corps appartient désormais à deux entités. D’une part, il dépend de ses camarades devant lesquels il doit 
prouver sa masculinité. D'autre part, ce corps masculin est au service de la nation pour laquelle il est censé se sacrifier. L'adoption de l'uniforme militaire équivaut dès lors, pour le personnage, à un changement de peau. Alors qu'il n'était qu'un individu, au cours de son apprentissage militaire Jorge Bello appartient désormais à un vaste ensemble qui le dépasse (Corbin et al. 2011: 68). Ainsi, dans la première partie du roman, la camaraderie occupe une place importante dans les mémoires du hérosnarrateur. Pour le jeune Bello, le corps constitue l'élément principal qui prouve et légitime sa masculinité. Comme nous l'avons vu précédemment, l'acquisition de la masculinité virile passe d'abord par le travail physique, afin de se conformer à l'imaginaire masculin hégémonique du soldat à la force herculéenne. En public, les jeunes gens doivent se forger une carapace visant à ne pas montrer de signes extérieurs pouvant faire penser à une éventuelle fragilité. Il est donc interdit à un homme de parler de ses affects et de ses souffrances, qu'il se doit d'intérioriser. Dès lors, le regard rétrospectif du narrateur sur son évolution s'attarde sur un événement caractéristique de la démonstration de sa virilité devant ses camarades : la perte de la virginité. Bello confie alors au lecteur les complexes qu'il avait durant son adolescence en raison de son inexpérience sexuelle :

Mais hélas, pendant deux mois de repos et de totale liberté pour mes camarades, je supposais déjà que leur carnet de conquêtes et d'aventures amoureuses devait être bien rempli et riche en péripéties, délicieuses pour eux et d'une humiliante réalité pour moi, qui ne pouvais pas même me prévaloir d'une seule conquête amoureuse, semblable à celles auxquelles mes camarades et mes amis accordaient tant d'importance ${ }^{15}$. (El Conspirador : 41)

Afin de perdre sa virginité, conçue par le héros-narrateur comme le monde de l'enfance, et mû par le désir d'être reconnu par ses pairs, il se tourne vers le monde de la prostitution : « [E]t je me disais à moi-même : - Une nuit d'orgie est la seule chose qui donne la certitude d'être un homme dans tous les sens du terme; courage donc, il faut être un tombeur, boire cul sec et séduire tout ce qui bouge ${ }^{16} »$ (El Conspirador : 54). Dans cet extrait, l'expression «se dire à soi-même " comme mode d'auto-persuasion démontre que la virginité est significative de la volonté du sujet de se plier aux normes de la masculinité hétérosexuelle (Schlagdenhauffen 2014: 74). La camaraderie masculine évoquée par le narrateur consiste dans ce roman en un discours partagé entre jeunes hommes qui exagèrent leur virilité en mettant en avant une sexualité débordante. Autrement dit, au sein de cette camaraderie, les hommes se regardent entre eux. Les corps masculins sont donc conçus dans ces mémoires comme les lieux d'interprétation de l'apprentissage et de légitimation de la masculinité (Laguardia $2008: 59)$.

11 Par le biais des réflexions du héros-narrateur sur la transformation de son propre corps pour correspondre à un idéal de masculinité virile, Mercedes Cabello de Carbonera met en relief l'idée que le corps masculin est certes jugé par les autres hommes mais qu'il est également dépositaire d'un sentiment collectif: l'amour pour la patrie par le sacrifice. En effet, selon Benedict Anderson, dans l'imaginaire nationaliste, la mort est le sacrifice ultime de l'individu pour la nation à laquelle il appartient ou à laquelle il s'identifie (Anderson [1983] 1996 : 24). La nation inspire l'amour, dont la forme la plus valorisée est le sacrifice de la vie (145). En Amérique latine, le concept de patrie au XIX siècle a occupé dans les discours et les écrits une position similaire à celle de la notion de liberté. La liberté représentait la condition nécessaire à la constitution des entités autonomes économiques, politiques et culturelles (Lander 2003 : 75). Pour Anderson, la nation et la patrie s'entremêlent étant donné que le patriotisme est synonyme de 
l'identification à la nation et que le patriote doit offrir sa vie pour elle de façon désintéressée. On perçoit cette idée dans El Conspirador lorsque Jorge Bello fait allusion aux amis de son oncle, qui fut lui aussi conspirateur mais durant l'époque indépendantiste (Alca Panigua 2007) :

Les vieux amis et compères de mes oncles avaient eux aussi été révolutionnaires, du temps où ce titre symbolisait le patriotisme, le courage et de grandes ambitions ; à l'époque où l'on conspirait pour conquérir l'indépendance de la patrie afin d'abolir la domination espagnole ${ }^{17}$. (El Conspirador : 22)

Le combat, l'honneur et parfois la mort dans le sacrifice pour la patrie sont dès lors interprétés par le personnage principal comme les éléments clés de la mise à l'épreuve de sa virilité (Corbin 2011 : 403). Pourtant, soulignons que le narrateur se réfère dans cet extrait à des faits révolus, ce qui implique que, dans le présent du héros, l'identification " patrie-amour » qu'engendre le concept de nation a désormais perdu sa signification auprès de ses concitoyens. Tandis qu'au temps de son oncle la révolution se pensait en termes patriotiques et désintéressés, elle est maintenant utilisée à des fins personnelles : «Arriver à être un caudillo comme lui, adulé par les hommes et désiré par les femmes était ma plus grande ambition ${ }^{18} "$ (El Conspirador : 62). La fascination du jeune Jorge Bello pour le culte de la personnalité généré par la figure du caudillo démontre qu'il n'est plus question de donner sa vie pour des idéaux mais uniquement d'accéder aux plus hautes sphères du pouvoir. Ainsi, dans la jeunesse du hérosnarrateur, le concept de nation n'est plus synonyme de camaraderie, de liberté et d'allégeance à un territoire mais plutôt de violence, d'autoritarisme et d'ambitions personnelles qui sont les fondements du caudillisme politique et militaire. C'est donc en utilisant la presse que le caudillo alimente sa vanité et raconte l'effet positif de ses prouesses militaires sur la communauté nationale (Alca Panigua 2007). Lorsqu'il écrit ses mémoires, Jorge Bello est parfaitement conscient de la nécessité que représentait la presse dans le soutien de sa candidature présidentielle. De fait, une nouvelle publiée dans un journal était immédiatement partagée par un autre membre de la " communauté imaginée ». Il écrit de façon très ironique : « Inutile de vous dire qu'il fut nécessaire de fonder un journal. Un candidat sans journal est comme un saint sans dévot $^{19} "$ (El Conspirador: 132). Dans El Conspirador, Mercedes Cabello de Carbonera montre que les chefs militaires qui accèdent au pouvoir le font grâce à l'usage de la force et à la manipulation de la presse.

Les liens entre la presse et l'imaginaire national ont amplement été mis en avant par Benedict Anderson. Selon lui, le « capitalisme de l'imprimé » a permis aux locuteurs de différentes langues de se comprendre et de fixer un langage commun via la technologie de l'imprimerie. En ce sens, le journal est l'instrument qui entretient les liens entre les membres d'une même nation à travers les informations (Anderson [1983] 1996 : 55). Au Pérou, si au XviII ${ }^{\mathrm{e}}$ siècle, le marché éditorial se composait presque exclusivement de livres, au XIX ${ }^{e}$ siècle, c'est la presse qui s'imposa. Le caractère condensé du journal facilita sa circulation au sein du lectorat, ce qui lui permit de conquérir un public de plus en plus important. Tout au long du XIX siècle, y compris avant l'indépendance du pays en 1821, la presse constitua au Pérou un réseau de communication clé pour les partis politiques. Ces derniers l'utilisaient comme organe de diffusion massif de leurs idées et pour la création d'un nouveau langage républicain au sein de la population. Les dirigeants politiques publiaient, entre autres, des textes dans un langage simplifié sous forme de questions-réponses dans le but d'orienter l'opinion du lecteur et de favoriser l'intériorisation des concepts politiques défendus. Autrement dit, les journaux furent 
un instrument de politisation de la société péruvienne (Ragas 2009: 43-54). Dans El Conspirador, l'opinion instable et le caractère manipulable à souhait de la presse est finalement le reflet d'une classe politique changeante, sans idéaux et intéressée par le maintien au pouvoir de l'oligarchie. Dans le récit du conspirateur, la politique péruvienne est un organe corrompu où ceux qui l'intègrent ne sont pas des patriotes mais des personnalités immorales et intéressées par l'ascension sociale. Ainsi, les conspirateurs empruntent le chemin de la politique pour se rendre maîtres de la nation. Dans ce roman, comme dans la conception nationale de Benedict Anderson, c'est à travers la presse que Bello raconte l'effet positif qu'a provoqué la nouvelle d'un journal qui sera ensuite partagée par un autre membre de la " communauté imaginée » (Anderson [1983] 1996) :

Moi qui étais de ceux qui attendaient ces bouleversements politiques, j'ai reçu avec une immense joie la nouvelle donnée par les journaux qui disaient: Révolution à Arequipa. Le conspirateur s'est proclamé Chef suprême de la République ${ }^{20}$ ! (El Conspirador : 60)

Dans El Conspirador, le journal assume également ce rôle de communion entre les membres de la nation car il est le lien entre Jorge Bello, ses partisans et ses opposants. De fait, beaucoup de ceux qui ne le connaissent pas et ne font pas partie de son cercle de fidèles prennent connaissance de son existence et de ses actions par le biais des informations du journal. Celui-ci permet donc de manipuler l'opinion publique et le conspirateur confesse à maintes reprises dans ses mémoires avoir utilisé la presse pour accéder au siège présidentiel (Alca Paniagua 2007) :

Pas une seule réunion politique ne s'est déroulée sans que je n'y assiste, et aucun journal d'opposition n'a vu le jour sans que je n'y déverse ma haine à l'égard de ministres, préfets et autres gouvernants dont je faisais la cible de mes aversions, simplement parce que je les considérais comme des entraves ou des obstacles à la réalisation de mes ambitions ${ }^{21}$. (El Conspirador : 58 )

Dans cet extrait, l'analogie qu'établit Jorge Bello entre la presse et ses ambitions personnelles souligne le caractère manipulable des journaux. De plus, le peuple est représenté de manière très dépréciative comme étant une masse analphabète formée d'Afro-descendants, d'Indiens et de Métis influençables. La turpitude de la politique péruvienne mise à jour par le récit à la première personne se situe à l'opposé de l'idéal de nation libre, moderne et souveraine que le héros-narrateur désire une fois adulte. C'est pourquoi à la fin de la première partie, la narration des épisodes traumatiques de la guerre vécus par le caudillo souligne la déshumanisation progressive du personnage au sein d'une nation sans valeurs ni principes à défendre :

Et lorsqu'en raison de mon statut militaire, je dus accepter l'impitoyable exigence

de tuer et de détruire, je sentais se défaire les fibres sensibles de mon âme.

[...] Le sang, dont les grands caillots formaient d'étranges dessins, se répandait sur le sol, imitant les larges zigzags d'une carte géographique.

Moi, je me sentais presque asphyxié par cette atmosphère infestée par l'odeur âcre du sang, chargée des émanations de ces corps de révolutionnaires, suants et désirés ${ }^{22}$. (El Conspirador : 66-73)

Dès lors, l'image du corps viril et puissant du caudillo désirée par le jeune Bello est finalement totalement désacralisée dans le regard critique du personnage adulte sur son propre passé. Au mépris de la lutte pour l'indépendance nationale menée par son oncle et ses camarades, dans le présent du jeune héros, la guerre n'est pas valorisée. À l'image des corps en état de putréfaction sur le champ de bataille, la nation sans honneur ni principes s'assimile à une forme de dégénérescence. 


\section{La « féminisation » du caudillo} perte de valeurs morales à travers le regard introspectif du héros-narrateur sur son processus de construction de caudillo. En revanche, dans la seconde partie du récit, la voix narrative se veut plus intimiste et sentimentale car elle s'intéresse à la relation amoureuse entre le héros Jorge Bello, devenu conspirateur militaire, et sa maitresse ofelia Olivas. Cette union devient pour la romancière le motif d'une réflexion sur la distribution des rôles sociaux entre les hommes et les femmes, dans la société péruvienne de son époque.

Le thème de la représentation du couple hétérosexuel a largement occupé le roman latino-américain du XIX ${ }^{e}$ siècle. Il incarnait l'élément de base nécessaire à la formation de la famille, elle-même imaginée par les libéraux latino-américains comme un microcosme de la nation. Le noyau familial constituait non seulement l'élément de médiation entre le domaine public et privé, mais il définissait également les rôles génériques entre les hommes et les femmes (Montero Sánchez 2002 : 17). L'intérêt des «penseurs de la nation » et des écrivains portait sur le rôle de ce noyau familial dans la formation du citoyen (Crespo Sánchez 2015 : 589). Dans Ficciones fundacionales. Las novelas nacionales de América latina, Doris Sommer explore la corrélation entre le roman romantique en vogue au $\mathrm{XIX}^{\mathrm{e}}$ siècle et l'histoire patriotique des jeunes nations d'Amérique latine :

Les romans issus du romantisme se sont développés simultanément avec l'histoire patriotique de l'Amérique latine. Ils ont conjointement éveillé un désir ardent de bonheur domestique qui a dérivé en rêves de prospérité nationale. Ces rêves se sont matérialisés à travers des projets de construction de nations, investissant les passions privées à des fins publiques ${ }^{23}$. (Sommer [1991] $2004: 150-151$ )

Bien que El Conspirador ne soit pas affilié au genre romantique sentimentaliste mais au contraire au réalisme social, la seconde partie du récit prend également en exemple les relations intimes du couple comme métaphore de la nation. Il convient de souligner qu'au sein de l'imaginaire national des libéraux latino-américains du xix ${ }^{\mathrm{e}}$ siècle, les rapports sociaux de domination entre les genres apparaissaient dans la fiction sous la forme d'espaces et de symboles différenciés entre les sexes. Le masculin s'assimilait à l'espace public, à la raison, à l'extériorité et à l'officiel, alors qu'on attribuait le féminin à l'espace privé, la soumission et la sensibilité (Bourdieu [1998] 2014 : 47-48). Sur le plan de la réception de l'œuvre littéraire, le constat est le suivant : il s'agissait de véhiculer des modèles sociaux que les hommes et les femmes étaient censés incarner (15-17). Comme le soutient Pierre Bourdieu, dans la logique de la domination masculine, « être féminine » consiste à éviter les pratiques et les signes associés à la virilité. Dans cette logique, le pouvoir reste associé à un attribut proprement masculin (136). Dans le roman El Conspirador, Mercedes Cabello de Carbonera se joue de ces stéréotypes genrés par un procédé d'inversion des rôles féminins et masculins entre ses personnages principaux: Ofelia Olivas se retrouve "masculinisée » tandis que Jorge Bello se « féminise ». Par les concepts de "féminisation » et « masculinisation » nous désignons le processus de transformation des personnages qui adoptent des traits de caractère généralement associés au sexe opposé (Cárdenas Moreno 2013 : 288). Pour ce qui est d'ofelia, prénom shakespearien autant évocateur d'amour que de tragédie, il s'agit d'un personnage aux multiples facettes. Premièrement, à travers les commentaires des personnages secondaires, elle est présentée au lecteur sous les traits d'un personnage 
féminin idéal. Elle pratique des activités caritatives et a supporté en silence les infidélités de son mari ainsi que ses excès de violence (Tauzin-Castellanos 1993 : 494). L'on dit donc d'elle que « cette femme est aussi honnête que belle [... $]^{24}$ » (El Conspirador : 158) et que c'est une «femme vertueuse » («mujer virtuosa», 160). Mais au fil du roman les origines sociales d'Ofelia apparaissent douteuses et le lecteur apprend qu'elle appartient à une famille dont la distinction sociale est liée à des affaires commerciales peu recommandables et à la prostitution de sa mère adoptive. Ensuite, Ofelia se marie avec un faux comte français qui a acheté son titre de noblesse et finit par l'abandonner. Elle est alors appelée « la petite comtesse du cocher » («Condesita del pescante », 160), à cause du métier exercé par son mari en France. Après la séparation du couple, elle est traitée comme une « veuve » ("viuda », 162) et c'est au contact du caudillo Jorge Bello qu'elle se «masculinise » et adopte les attitudes égoïstes, agressives et corrompues des conspirateurs masculins. Elle prend finalement la tête du parti politique de Bello, passant radicalement du statut de "femme vertueuse " (160) à celle de "Colonelle Bella " ("Coronela Bella », 261) : "En public et entre amis, on lui donnait le nom de Colonelle Bella, mettant mon nom de famille au féminin ${ }^{25}$ " (242).

Alors que dans la littérature hégémonique du XIX ${ }^{e}$ siècle le personnage féminin était associé à la passivité, c'est l'inverse qui se produit dans ce roman avec Ofelia Olivas. C'est bel et bien ce personnage féminin qui est au cœur des péripéties du roman : elle organise l'évasion de Jorge Bello de la prison, après sa tentative de coup d'État, elle reprend la tête du parti politique et n'hésite pas à se prostituer avec ses anciens partisans afin de subvenir aux besoins du foyer. La fonction de chef politique d'Ofelia est utilisée par la romancière comme stratégie littéraire d'inversion des espaces attribués au "masculin» et au "féminin ». Dans ce roman, le personnage féminin transgresse la figure idéale de l'« ange du foyer » (ángel del hogar ${ }^{26}$ ) très en vogue dans les romans latino-américains du XIX ${ }^{e}$ siècle. Le champ d'action d'Ofelia n'est pas limité au foyer mais se replace au contraire dans l'espace public, habituellement réservé aux hommes. Si dans La domination masculine Pierre Bourdieu considère que les femmes sont soumises à une sorte d'« enclos invisible » qui limite leurs mouvements à l'espace privé (Bourdieu [1998] 2014: 47), dans El Conspirador cet état d'enfermement est paradoxalement subi par le héros-narrateur :

Ma dignité et mon amour-propre se sentaient cruellement diminués : vivre aux dépens d'une femme est la pire des ignominies pour un homme distingué. [...]

- Ne sors pas Ofelia, je t'en supplie; ne sors pas seule quand il fait nuit.

- Ah! Arrête donc avec tes interdictions sans but. Tu comprendras que je sors uniquement pour m'occuper de toi. Je serai de retour très bientôt. À plus tard... À plus tard !...

Et tout en se libérant de mon étreinte, elle sortit précipitamment ${ }^{27}$. (El Conspirador : 252-254)

Dans la première partie du roman, le courage et l'action sont pour le héros-narrateur des signes de virilité, alors que dans cette seconde phase du récit, c'est le personnage féminin qui montre le plus d'aplomb dans les situations critiques. De même, on observe également un léger glissement de la voix narrative, jusqu'ici entièrement dominée par les mémoires de Jorge Bello, qui laisse place aux discours d'Ofelia Olivas (Cárdenas Moreno 2013 : 495). Dans ce roman, le processus de «masculinisation» du personnage féminin est étroitement lié à son union avec le caudillo dont elle adopte les caractéristiques - l'ambition démesurée, l'individualisme et l'agressivité :

- Bah! Ne me parle pas de moralité ici dans cette société ; ça valait encore quand je n'étais qu'une grande naïve qui ne comprenait rien à rien ; la preuve est que je n'ai 
jamais eu autant d'amis et d'adorateurs que maintenant. Et en ce qui te concerne, tu penses peut-être que tu es le seul homme public qui vit éhontément avec une femme mariée et reçoit courrier et amis chez sa maîtresse ? [...]

Écoute, moi si j'étais à ta place, je mettrais le feu aux poudres dès demain et je me proclamerais Président de la République. Oh! que les hommes sont lâches ${ }^{28}$ ! (El Conspirador : 196 et 208).

Dans cet extrait, force est de constater que « la Colonelle Bella » (261) est bien loin de l'idéal patriotique des héros de l'indépendance qui se battaient pour défendre la liberté et la souveraineté nationale. Pour Ofelia, c'est par l'usage de la force et non des idées que l'on s'impose en politique. En tant que femme, Ofelia utilise la politique à des fins personnelles; elle veut arriver à tout prix au sommet du pouvoir et en viendra même à vendre son propre corps. Dans El Conspirador, la prostitution est la métaphore d'une nation sans idéaux ni valeurs morales: les actions des individus sont motivées par l'intérêt personnel. Cette perspective est évoquée dans la première partie du roman à travers l'analyse politique du mémorialiste Jorge Bello sur sa formation de caudillo : « À Lima, nous, les hommes publics, nous devons nous comporter comme les femmes publiques ; manger autant de fois qu'il le faut pour séduire un ami ${ }^{29}$ " (El Conspirador : 131). En effet, dans El Conspirador, ce ne sont pas seulement les femmes qui se prostituent mais également, de façon métaphorique, les hommes politiques sous l'effet d'une société corrompue qui encourage les individualismes. Il faut souligner qu'à partir de la seconde moitié du $\mathrm{XIX}^{\mathrm{e}}$ siècle jusqu'au milieu du $\mathrm{xx}^{\mathrm{e}}$ siècle, sous l'influence $\mathrm{du}$ mouvement littéraire naturaliste européen, de nombreux auteurs hispano-américains ont conçu le personnage de la prostituée comme l'emblème du déterminisme génétique et de la dégradation morale de la société. L'on peut citer entre autres, Música sentimental (1884) de l'Argentin Eugenio Cambaceres ou encore Santa (1903) du Mexicain Federico Gamboa. Ce dernier, par exemple, considère la prostitution de Santa comme un « instinct » hérité de ses ancêtres : « il est fort probable qu'elle porte dans son sang les germes d'une très ancienne lascivité héritée d'un quelconque arrière-arrière-grandpère qui ressuscitait en elle avec vices et tout le reste ${ }^{30}$ "(Gamboa [1903] 1992 : 76). Dans le cas d'Ofelia, la thèse du déterminisme génétique est évoquée dans la bouche d'un personnage secondaire qui affirme à son sujet : " la fille de la prostituée est ellemême une prostituée [...], c'est la loi immuable de la nature [... ${ }^{31} »$ (El Conspirador : 163). Pourtant, le lecteur apprend que la mère prostituée d'ofelia est en réalité sa tante qui l'a adoptée, ce qui signifie qu'elle ne peut pas hériter de ses vices. La prostitution, qui affecte dans ce roman aussi bien les femmes que les hommes, est donc envisagée en termes de déterminisme social. En ce sens, Ofelia est un personnage féminin qui se fait l'écho de l'héroïne de Blanca Sol (1889), l'avant-dernier roman de Mercedes Cabello de Carbonera. Aussi bien El Conspirador que Blanca Sol appartiennent à un même projet de critique sociale et politique car Ofelia et Blanca incarnent des personnages féminins qui se prostituent non pas en raison d'un héritage génétique dégradé mais plutôt comme la conséquence d'une société corrompue et individualiste. Dans la seconde partie de El Conspirador, Jorge Bello, enfermé dans l'espace domestique, file la métaphore de la « femme publique » et écrit avec dégoût : « [...] [J]e peux manger grâce à la prostitution de la femme que j'aime ${ }^{32}$ » (257). Le processus de "féminisation » du caudillo Jorge Bello est conçu dans le roman comme une forme de dévirilisation qui le vide complètement de son pouvoir d'action. Forcé de vivre caché pour échapper aux autorités, le caudillo devient un «homme au foyer » en proie à des crises de larmes, sensible et amoureux. Le personnage principal adopte dans cette seconde partie du 
récit des réactions qui, traditionnellement, caractérisent le comportement des héroïnes, comme le fait d'avoir des crises de nerfs et d'être dominé par ses passions.

Ensuite, dans ces circonstances, le système nerveux constamment survolté fragilise le corps et augmente l'angoisse. Je me sentais mourir. [...] La vie inactive, solitaire, accablée par le souvenir des mille déceptions qui m'entouraient, avait tellement excité ma passion, que j'aurais voulu seulement vivre pour épier les actions d'ofelia $[\ldots]^{33}$. (El Conspirador : 230 et 248)

17 Comme le souligne Mónica Cárdenas Moreno, la «féminisation» du caudillo se situe d'abord à un premier niveau : le processus de ridiculisation par l'adoption d'attitudes féminines considérées comme affaiblissantes. Puis, la « féminisation » de Jorge Bello se situe également à un second niveau: l'identification du héros avec la figure de la romancière (284-291). Jorge Bello devient le porte-parole des idées de Mercedes Cabello de Carbonera en ce qui concerne l'avenir national et la conception de la littérature. Dès le début de son récit, le héros-narrateur envisage son expérience personnelle de caudillo déchu selon un angle correctif. L'enjeu de l'écriture est l'union de l'expérience personnelle et de l'analyse sociale, de façon à corriger les défauts de la société : "Laisser à la génération qui nous succède l'exemple d'une vie, qui soit un avertissement pour se prémunir contre les embûches et les écueils que l'on rencontre dans le monde, tel doit être l'objectif de ce genre de publications ${ }^{34} »$ (7). Cette conception sociale de l'œuvre littéraire avait déjà été développée par Mercedes Cabello de Carbonera dans son essai la Novela Moderna. Estudio filosófico (1892). Elle y définit un nouveau type de littérature nationale qui s'oriente vers un réalisme balzacien capable d'allier la critique sociale et l'expression des sentiments :

$\mathrm{Au}$ sein des fictions romantiques et des créations fantastiques de cette école, est apparu Balzac, et, avec son œil de lynx, son esprit analytique et son génie de philosophe, il a sondé les recoins les plus secrets du cœur... Il porte sa puissante loupe, non pas pour observer, comme Zola, le corps exposé de façon luxuriante, ou la fatalité qui guide toute une génération d'irresponsables; mais pour raconter les émois du cœur et étudier les décharges passionnelles qui agitent l'esprit humain par une force irrésistible ${ }^{35}$. (Cabello de Carbonera 1892 [1948] : 36-37)

Par ailleurs, utilisant le masque du " travestissement ${ }^{36}$ » littéraire, la romancière met dans la bouche de son personnage principal masculin ses propres idées sur la revalorisation des femmes dans l'espace public:

Avec toute la véracité qui me caractérise, je dirai seulement qu'elles me semblèrent [les femmes] bien supérieures aux hommes. Il est vrai qu'en règle générale, le Pérou me semble présenter une anomalie singulière : non seulement les femmes y sont bien supérieures aux hommes intellectuellement et moralement, mais également physiquement ${ }^{37}$. (El Conspirador : 189)

18 Ainsi, si la «féminisation » de Jorge Bello le place du côté du ridicule dans un premier temps, et si la masculinisation d'ofelia est critiquée, cela entre dans l'objectif correctif que Cabello de Carbonera veut donner à son roman. À première vue, on pourrait penser qu'avec le personnage ambitieux et vaniteux que devient Ofelia, la romancière rejette l'idée de l'insertion des femmes en politique. Il n'en est rien, car ce que remet en question Mercedes Cabello de Carbonera, c'est avant tout le type de masculinité virile du caudillo qui est source de conflits. Au contraire, la personnalité d'Ofelia évolue plus vite que celle du mémorialiste Jorge Bello, qui a besoin de plusieurs mois d'enfermement dans sa cellule pour comprendre les conséquences de son comportement individualiste. Atteinte d'une tuberculose, sur son lit de mort, ofelia Olivas abandonne elle aussi la figure du caudillo, qui n'a fait qu'accélérer sa déchéance, pour devenir la voix de la sagesse du roman : 
Ce que tu as fondé n'était pas un parti fort et uni, mais un simple regroupement de spéculateurs et d'hommes vils, qui prenaient plaisir à t'acclamer uniquement dans le but de s'enrichir, s'ils atteignaient le triomphe suprême.

$\mathrm{Tu}$ seras surpris que j'utilise un tel langage, inapproprié dans la bouche d'une femme ; il faut dire qu'il y a des années, lorsque tu m'as lancée dans la ronde de tes partisans, j'ai beaucoup observé et j'ai appris plus encore. Si je ne t'ai pas parlé plus tôt avec une telle clarté, c'est parce que jusqu'à présent, tout comme toi, je me sentais enivrée et attirée par la ferveur de l'adulation. [...]

Si tu veux connaître la véritable grandeur et la prospérité, sois loyal et honnête dans la vie publique, franc et bienveillant dans la vie intime... ${ }^{38}$ (El Conspirador: 280-281)

Même si la prostitution est envisagée dans ce roman comme le signe de la déchéance sociale du personnage féminin, elle représente également un parcours de vie marginal qui lui confère un regard critique sur la société. De fait, la prostituée Ofelia se construit en tant que subjectivité féminine non pas fixe, conforme à l'idéal de l'ángel del hogar, mais au contraire aux frontières mouvantes dans un constant va-et-vient entre abjection et admiration. En ce sens, la construction « nomade » de la subjectivité de la prostituée lui permet de formuler une réflexion qui lui est propre à l'encontre d'une société patriarcale qui maintient les hommes et les femmes dans des rôles convenus ou bien les exclut, s'ils s'éloignent de ces rôles.

\section{Conclusion}

El Conspirador constitue par l'utilisation du «je» fictionnel masculin une forme de «témoignage » romancé du processus de formation de la virilité masculine et de celle de l'imaginaire national, dans la société péruvienne de la seconde moitié du XIX siècle. La dimension intimiste du récit à la première personne du singulier et celle, collective, du roman-mémoire témoignant d'une situation politique donnée sont utilisées par la romancière afin de mettre en lumière le mécanisme de construction de la masculinité hégémonique et ses retombées sur l'ensemble de la nation. Le dévoilement de l'expérience personnelle du héros-narrateur par l'écriture du «je » sur sa vie de caudillo, de même que la "féminisation » de cette figure sont des procédés littéraires qui font valoir l'idée que la masculinité virile n'est aucunement naturelle, mais qu'il s'agit au contraire d'un modèle monochrome auquel certains hommes peinent parfois à se conformer (Sohn 2009: 132). Dans ce roman, la puissance physique, l'ambition, l'autoritarisme et le militarisme qui fondent la figure du caudillo mettent gravement en péril la souveraineté de la nation péruvienne. À travers le récit de la déchéance morale et sociale du conspirateur Jorge Bello, la romancière indique à son public lecteur que les liens fraternels censés définir la nation s'évanouissent face aux intérêts personnels générés par le type de masculinité agressive du caudillo militaire. Autrement dit, dans El Conspirador, la représentation de la désacralisation de la virilité du caudillo constitue pour la romancière une façon de suggérer, à partir de la fiction, une nouvelle éthique du citoyen moderne. La transformation du caudillo agressif en écrivain de ses propres faiblesses est significative des valeurs morales du citoyen idéal selon Cabello de Carbonera: la réflexion critique, l'honnêteté et l'abnégation. De même, la grandeur morale d'Ofelia et sa capacité d'analyse légitiment l'idée selon laquelle les femmes ont vocation à agir en dehors de la sphère domestique, de la même façon que les écrivaines de l'époque s'intéressaient dans leurs écrits à des débats relatifs à la sphère publique. 


\section{BIBLIOGRAPHIE}

Alca Paniagua, Victoria, 2007, « La comunidad imaginada en El conspirador », Letralia, $\mathrm{n}^{\circ} 176$, 19 novembre 2007, [En ligne], https://letralia.com/176/articulo04.htm, consulté le 21 novembre 2019.

Anderson, Benedict, [1983] 1996, L'Imaginaire national. Réflexions sur l'origine et l'essor du nationalisme, Paris, La Découverte.

Beaulieu, Jean-Philippe et Oberhuber, Andrea, 2011, Jeu de masques. Les femmes et le travestissement textuel (1500-1940), Saint-Étienne, Publications de l'Université de Saint-Étienne.

Bourdieu, Pierre, [1998] 2014, La Domination masculine, Paris, Éditions Points.

Cárdenas Moreno, Mónica, 2013, Genre et société à Lima pendant la seconde moitié du XIXe siècle. Analyse de l'œuvre de Mercedes Cabello de Carbonera (1842-1909), Thèse de doctorat, Université Michel de Montaigne, Bordeaux 3.

Corbin, Alain, Courtine, Jean-Jacques, Vigarello, Georges, Airau, Paul, Audoin-Rouzeau, Stéphane et Bertaud, Jean-Paul, 2011, Histoire de la virilité. 2 Le triomphe de la virilité. Le XIX ${ }^{e}$ siècle, Paris, Seuil. Connell, Raewyn, 2014, Masculinités. Enjeux sociaux de l'hégémonie, Paris, Éditions Amsterdam.

Crespo Sánchez, Francisco Javier, 2015, « La familia sentimental: imágenes y discursos en la prensa del siglo XIX », Mediterranea, $n^{\circ} 35$, p. 585-616.

Demoris, René, 2002, Le Roman à la première personne du classicisme aux Lumières, Genève, Droz.

Farges, Patrick, 2014, « Récits de vie, stratégies narratives et constructions de la masculinité. Le cas des exilés germanophones en Palestine/Israël après 1933 ", dans B. Banoun, A. Tomiche et M. Zapata (dir.), Fictions du masculin dans les littératures occidentales, Paris, Classiques Garnier, p. 83-96.

Ferguson, Gary (dir.), 2009, Itinéraires. Littérature, textes, cultures, numéro inaugurale, « L'homme en tous genres. Masculinités, textes et contextes », Paris, L'Harmattan.

González Stephan, Beatriz, 2010, « Héroes nacionales, Estado viril y sensibilidades homoeróticas ", dans A. Peluffo et I. M. Sánchez Prado (dir.), Entre hombres: masculinidades del siglo XIX en América Latina, Madrid, Iberoamericana-Vervuert, p. 23-58.

Laguardia, David, 2009, « L'écriture polymorphe de la masculinité chez Rabelais », Itinéraires. Littérature, textes, cultures, numéro inaugural, p. 49-61, [En ligne], http:// journals.openedition.org/itineraires/2205, consulté le 21 novembre 2019. DOI : $10.4000 /$ itineraires.2205

Lander, María Fernanda, 2003, Modelando corazones. Sentimentalismo y urbanidad en la novela hispanoamericana del siglo XIX, Rosario, Beatriz Viterbo.

Lejeune, Philippe, 1975, Le Pacte autobiographique, Paris, Seuil.

Licón Villalpando, Azuvia, n. d., « Construir la nación en el siglo XIX latinoamericano: novela nacional e historia », [En ligne], https://www.academia.edu/8840477/, consulté le 21 novembre 2019.

Miraux, Jean-Philippe, [1996] 2007, L'Autobiographie. Écriture de soi et sincérité, Paris, Armand Colin. 
Montero Sánchez, Susana A., 2002, La construcción simbólica de las identidades sociales: un análisis a través de la literatura mexicana del siglo XIX, México, D.F. Universidad Nacional Autónoma de México, PUEG.

Peluffo, Ana, 2004, «Bajo las alas del ángel de caridad: indigenismo y beneficencia en el Perú Republicano ", Revista Iberoamericana, $n^{\circ}$ 206, p. 103-116.

Peluffo, Ana et Sánchez Prado, Ignacio M. (dir.), 2010, Entre hombres: masculinidades del siglo XIX en América Latina, Madrid, Iberoamericana-Vervuert.

Pratt, Mary Louise, 1999, « Repensar la modernidad », Espiral, vol. 5, n 15, p. 42-72.

Ragas, José, 2009, « Prensa, política y cultura impresa en el Perú, 1810-1872 », dans M. Velázquez Castro, La República de papel: política e imaginación social en la prensa peruana del siglo XIX, Lima, Universidad de Ciencias y Humanidades Fondo Editorial, p. 43-66.

Ramos, Julio, 1989, Desencuentros de la modernidad en América Latina, literatura y política en el siglo XIX, México, Fondo de Cultura Económica.

Schlagdenhauffen, Regis, 2014, « L'écriture de l'entrée dans la sexualité dans le Journal intime inédit d'Eugène Wilhelm », dans B. Banoun, A. Tomiche et M. Zapata (dir.), Fictions du masculin dans les littératures occidentales, Paris, Classiques Garnier.

Sohn, Anne-Marie, 2009, « Sois un homme! » La construction de la masculinité au XIXe siècle, Paris, Seuil.

Sommer, Doris, [1991] 2004, Ficciones fundacionales. Las novelas nacionales de América latina, Colombia, Fondo de Cultura Económica.

Tauzin-Castellanos, Isabelle, 1993, « Politique et hérédité dans El Conspirador de Mercedes Cabello de Carbonera (1892)», Bulletin hispanique, nº 95-1, p. 487-499, [En ligne], www.persee.fr/doc/ hispa_0007-4640_1993_num_95_1_4798.

DOI : 10.3406/hispa.1993.4798

Tauzin-Castellanos, Isabelle, 1995, « La narrativa femenina en el Perú antes de la Guerra del Pacífico », Revista de Crítica literaria latinoamericana, $\mathrm{n}^{\circ}$ 42, p. 161-187.

Thommeret, Loïc, 2006, La Mémoire créatrice, Paris, L'Harmattan.

\section{Corpus}

Cabello de Carbonera, Mercedes, 1892, El Conspirador. Autobiografía de un hombre público. Novela político-social, Lima, Imprenta de la Voce d'Italia.

Cabello de Carbonera, Mercedes, [1892] 1948, La Novela Moderna. Estudio filosófico, Lima, Hora de los Hombres.

González Prada, Manuel, [1908] 1985, Horas de lucha, Caracas, Biblioteca Ayacucho.

Gamboa Iglesias, Federico, [1903] 1992, Santa, México, Grijalbo.

Cambaceres, Eugenio, [1884] 1994, Música sentimental, Buenos Aires, Editorial Losada. 


\section{NOTES}

1. Il s'agit de notre traduction; nous retranscrivons le texte en version originale cidessous : "Para el escritor/estadista no existía una clara distinción epistemológica entre el arte y la ciencia, la narrativa y los hechos y, en consecuencia, entre las proyecciones ideales y los proyectos reales. »

2. Le concept de "roman national » est développé par Doris Sommer dans son ouvrage critique Ficciones fundacionales. Las novelas nacionales de América latina (1991). Il s'agit d'un type de roman né au XIX ${ }^{e}$ siècle qui mettait en scène une histoire d'amour entre un homme et une femme appartenant à différentes classes sociales, économiques et "raciales». Les obstacles affrontés par le couple hétérosexuel représentaient une allégorie des sociétés latino-américaines et de leur projet de construction nationale.

3. Dans son important article sur l'émergence du roman féminin péruvien, Isabelle Tauzin-Castellanos (1995) affirme que ce rythme lent se perpétue après la guerre. Sur une période de vingt ans, seule une vingtaine de romans sont édités dont plus de la moitié ont été signés par des femmes.

4. Le guano, qui vient du quechua " wanu » est un fertilisant naturel très efficace à base d'excréments d'oiseaux marins et de chauves-souris. Au Pérou, son exploitation s'est développée dans les zones côtières rocheuses et les îles.

5. Le terme de «caudillo» a évolué au fil du temps. À l'époque de l'Espagne de la Reconquête, le caudillo était avant tout un chef de guerre qui dirigeait sa propre armée. En Amérique latine, après les guerres d'indépendance, en raison des conflits entre différents groupes pour la conquête du pouvoir, le terme de "caudillo » finira par désigner un leader politique, militaire et/ou idéologique. Du point de vue politique, l'arrivée au pouvoir du "caudillo" se caractérise le plus souvent par l'usage de la violence, notamment par le biais du coup d'État ou encore à l'issue d'un processus révolutionnaire. Le régime instauré par le caudillo est de nature autoritaire. Contrairement au dictateur, le caudillo bénéficie essentiellement du soutien des masses populaires au nom des valeurs qu'il incarne sans pour autant forcément définir une orientation politique fixe.

6. Le terme «montanero » désignait les troupes de Nicolás de Piérola (1839-1913), essentiellement composées d'Indigènes et de Métis issus des provinces du Pérou. Ces dernières l'ont aidé à perpétuer son coup d'État militaire à Lima contre le président Andrés Avelino Cáceres (1833-1923) en 1895.

7. Nous précisons que le texte "Nuestros Indios » a certainement été écrit, de façon partielle, en 1904. Il a été incorporé dans le recueil d'essais Horas de Lucha en 1908. Il s'agit de notre traduction; nous retranscrivons ci-dessous la version originale : « La condición del indígena puede mejorar de dos maneras: o el corazón de los opresores se conduele al extremo de reconocer el derecho de los oprimidos, o el ánimo de los oprimidos adquiere la virilidad suficiente para escarmentar a los opresores. Si el indio aprovechara en rifles y cápsulas todo el dinero que desperdicia en alcohol y fiestas, si en un rincón de su choza o en el agujero de una peña escondiera un arma, cambiaría de condición, haría respetar su propiedad y su vida. A la violencia respondería con la violencia, escarmentando al patrón que le arrebata las lanas, al soldado que le recluta en nombre del gobierno, al montonero que le roba ganado e bestias de carga. Al indio no se le predique humildad y resignación, sino orgullo y rebeldía. » 
8. Nous attirons l'attention du lecteur sur le fait qu'il s'agit d'une traduction personnelle, le texte n'ayant pas fait l'objet d'une édition française. En notes de bas de page, le lecteur pourra se référer aux passages analysés du roman en version originale.

9. Citation en version originale: «Quiero publicar estas memorias. Quizá sean de alguna utilidad para mis contemporáneos; quizá puedan servir de ejemplo a aquellos que, fascinados por las riquezas adquiridas fácilmente, impulsados por los especuladores que rodean a los hombres públicos, y extraviados por sus propias pasiones, crean como yo creía, que el camino seguro, es el de los fraudes y las especulaciones, lleno de encrucijadas y peligros, y no el camino ancho, luminoso, expuesto a todas las miradas, y asegurado contra todas las caídas. Sí, publicaré estas memorias, y la confesión pública de mis faltas, quizá me devuelva la serenidad de ánimo que he perdido!... »

10. «Trataré de recopilar los acontecimientos más notables y trascendentales de mi vida. El esfuerzo de la memoria, me ocupará a todas las horas, y cuando no escriba pensaré. »

11. «Bien quisiera prescindir de esta historia de mis primeros años, pero la juzgo necesaria para explicar las mil anomalías que hay en mi vida; y también el lado algo dramático que en ella se ha de encontrar. »

12. "Yo nací tan débil y raquítico, que nadie esperaba verme cumplir ni aún una treintena de días. [...] Cuando llegué a los cinco años, mi tía, (luego hablaré de ella) refiriéndose a mi endeble constitución física, solía decir: - Como el pobrecito es sietemesino, es natural que sea delicado y enfermizo. Mi raquitismo, lejos de ser corregido por una educación vigorizante y de continuo ejercicio, fue fomentado por el excesivo mimo y el cariño tolerante de mis tíos. »

13. «Yo mismo, cuánto no he ansiado alcanzar la fortaleza corporal que, muchas veces, en mi activa vida política, faltóme, con grandes daños de mis planes y empresas de hombre público! Aún en mi carrera militar, me ha perjudicado grandemente mi pequeña estatura, y mi débil y delicada constitución física. »

14. «Cuando cumplí quince años, era ya un mozancón muy espigado, y muy dado a hombrearme con mozos mayores que yo, y todo aquel raquitismo que mi tía explicaba con el feo y antipático calificativo de sietemesino había desaparecido casi del todo; y aunque conservaba mi constitución delicada y nerviosa, sentía ya los primeros destellos de la edad viril, que rápidamente se manifestaba en mí. Las atipladas inflecciones de mi voz, principiaron a desafinarse, como cuerdas que al engrosar, hubiéranse tornado broncas y sonoras. [...] [A]pareció el vello viril, dibujando el bozo, y sombreando las mejillas.»

15. «Pero ¡ay! en dos meses de holganza, y completa libertad para mis compañeros, ya me suponía que su catálogo de conquistas y amoríos había de ser abundantísimo y lleno de lances, deliciosos para ellos y, de humillante realidad para mí, que no podía contar ni con una sola conquista amorosa, de aquellas que tanta importancia daban a mis compañeros y amigos. »

16. « [Y] me decía a mí mismo: - Una noche de orgía es lo único que da la convicción de ser hombre en toda la extensión de la palabra; ánimo pues, es necesario ser calavera, beber sin tasa y enamorar a roso y belloso."

17. «Los viejos amigos y contertulios de mis tíos, habían sido también revolucionarios, de aquel tiempo en que este título simbolizaba patriotismo, valor y grandes de miras; 
cuando se conspiraba para conquistar la independencia de la patria, dando fin con la dominación española. »

18. «Llegar a ser un caudillo como él, adulado por los hombres y mimado por las mujeres, era la ambición más vehemente de mi alma. "

19. «No necesito decir que fue necesario fundar un periódico. Un candidato sin periódico es como santo sin devoto.»

20. "Yo que era uno de los que aguardaban esas conmociones políticas, escuché con grande regocijo la nueva dada por los periódicos que decían: Revolución en Arequipa. ¡El conspirador se ha proclamado Jefe supremo de la República! »

21. « No hubo reunión política a la que yo no asistiera ni periodiquillo de oposición que se fundara, en el que yo me desataba contra ministros y perfectos y demás gente palaciega, a quienes detestaba convirtiéndolos en blanco de mis aversiones, tan sólo por considerarlos impedimentos u obstáculos a la realización de mis ambiciones. "

22. "Y cuando en mi condición de militar, debía aceptar la guerrera imposición de matar y destruir, sentía romperse las fibras sensibles de mi alma. [...] La sangre, formando caprichosos dibujos con sus grandes coágulos, corría en el suelo, simulando una carta geográfica en sus largos culebreos. Yo me sentía casi asfixiado, respirando aquella atmósfera saturada del olor acre de la sangre, recargada con las emanaciones de aquellos cuerpos, sudorosos y deseados como estaban los revolucionarios. »

23. Il s'agit de notre traduction ; nous retranscrivons le texte en version originale cidessous: "Las novelas románticas se desarrollaron mano a mano con la historia patriótica de América latina. Juntas despertaron un ferviente deseo de felicidad doméstica que se desbordó en sueños de prosperidad nacional materializados en proyectos de construcción de naciones que invistieron a las pasiones privadas con objetivos públicos. "

24. «Pues esa mujer es tan honrada como hermosa [...]. »

25. «En el público y entre mis amigos, se le daba el nombre de la Coronela Bella, poniendo mi apellido en femenino. »

26. Le concept d'ángel del hogar a été inventé par l'Anglais Coventry Patmore (1823-1896) dans son poème The Angel in the House publié en 1854 au Royaume-Uni et dont la diffusion s'est étendue bien au-delà des frontières européennes. Cette image de « l'ange du foyer » consistait en l'apologie de la figure féminine en tant que gardienne morale de l'espace domestique en raison de sa condition d'épouse et mère de citoyen. Parmi les vertus qui la définissaient, il faut citer la pitié et l'abnégation féminine, qui étaient assimilées à la charité chrétienne.

27. « Mi dignidad y mi amor propio, sentíase cruelment e lastimados: vivir a expensas de una mujer, es la mayor ignominia para un hombre delicado. [...] - No salgas Ofelia yo te lo ruego; no salgas sola de noche. - ¡Hé! Déjate de exigencias sin objeto; ya verás que yo solo salgo por ocuparme de ti. Muy pronto voy a regresar. ¡Hasta luego...hasta luego!... Y escurriéndose de entre mis brazos salió precipitadamente.»

28. « - ¡Bah! No me hables de moralidad aquí en esta sociedad; eso estaba bueno para cuando yo era una inocentona que nada comprendía; la prueba es que nunca tuve tantos amigos y aduladores como ahora: y lo que es respecto a ti, eres acaso el único hombre público que vive escandalosamente con una mujer casada y recibe cartas y amigos en casa de su querida?... [...] Mira, si yo estuviera en tu lugar, mañana mismo 
pusiera fuego a la mina, y me proclamaría Presidente de la República. ¡Oh! qué cobardes son los hombres! »

29. «En Lima, los hombres públicos necesitamos ser como las mujeres públicas; comer tantas veces cuántas sea necesario para conquistar a un amigo. »

30. « es de presumir que en la sangre llevara gérmenes de muy vieja lascivia de algún tatarabuelo que en ella resucitaba con vicios y todo."

31. « la hija de la prostituta es prostituta [...], es ley invariable de la naturaleza. »

32. «[E]stoy comiendo con la prostitución de la mujer a la que amo.»

33. "Y luego, en estas circunstancias, el sistema nervioso continuamente excitado, enferma el cuerpo y aumenta la angustia. Yo me sentía morir. [...] La vida inactiva, solitaria, agobiaba por el recuerdo de las mil decepciones que me rodeaban, había de tal suerte enardecido mi pasión, que ya yo sólo hubiera querido vivir para espiar las acciones de Ofelia [...].»

34. «Dejar a la generación que nos sucede el ejemplo de una vida, que sea un aviso para precautelarse contra los sirtes y escollos en que en el mundo encontraos, debe ser el móvil de este género de publicaciones. »

35. Il s'agit de notre traduction; nous retranscrivons la version originale ci-dessous : «En medio a las ficciones románticas y las creaciones fantásticas de esa escuela, apareció Balzac, y con su mirada de águila, con su espíritu analítico y su genio de filósofo, sondeó los más secretos resortes del corazón... El lleva sus lentes de poderosa potencia, no para mirar, como Zola, el cuerpo desnudo estremeciéndose lujuriosamente, o la fatalidad guiando a toda una generación de irresponsables; sino para contar las palpitaciones del corazón; y estudiar las sacudidas pasionales que con irresistible fuerza, agitan el espíritu humano. »

36. Le terme de "travestissement » que nous utilisons se réfère au sens figuré de l'acte de travestir, soit l'action de transformer ou d'altérer la nature de quelque chose ou de quelqu'un. Le "travestissement" littéraire que nous employons ici est le fait pour l'auteur d'adopter une identité qui n'est pas la sienne, notamment en ce qui concerne le genre, par le biais de l'écriture. Dans ce domaine, les femmes ont souvent eu recours au «travestissement » ou encore à la dissimulation de leur véritable identité dans le but d'en créer une autre différente de celle qui leur était généralement attribuée. Dans le cas d'El Conspirador, nous considérons que le choix d'un héros-narrateur masculin de la part de la romancière, pour légitimer sa prise de position sur la politique péruvienne, entre dans ce cadre de trouble des repères identitaires. Pour plus d'informations à ce sujet, voir Beaulieu et Oberhuber (2011).

37. "Con la veracidad que acostumbro, diré solo, que ellas me parecieron muy superiores a ellos. Verdad que por regla general, paréceme que en el Perú, acontece la singular anomalía de ser, no solo en cualidades morales e intelectuales, sino también en condiciones físicas, muy superiores las mujeres a los hombres. »

38. «Lo que tú fundaste no fue un partido fuerte y compacto, sino solo una agrupación de especuladores, de hombres viles, que complacían en adularte con el fin de medrar, si alcanzaban el triunfo definitivo. Te asombrarás de que yo te hable este lenguaje impropio en los labios de una mujer; es que hace años, desde que tú me lanzaste en el torbellino de tus partidarios, he observado mucho y he aprendido mucho más. Si antes no te he hablado con esta claridad, es porque entonces, yo también como tú, me sentía mareada y desvanecida con el incienso de la adulación. [...] Si quieres y aspiras a la 
verdadera grandeza y prosperidad, sé leal y honrado en la vida pública, franco y bondadoso en la vida íntima... »

\section{RÉSUMÉS}

La guerre du Pacifique (1879-1883) a représenté au Pérou un conflit majeur qui a marqué la façon dont les écrivains concevaient la littérature et la nation. Au cours de la période d'après-guerre se succèdent les caudillos sur le siège présidentiel. Dans les discours des intellectuels péruviens, la figure du soldat vindicatif devient un emblème de masculinité idéale. C'est dans ce contexte conflictuel que l'écrivaine péruvienne Mercedes Cabello de Carbonera (1842-1909) publie en 1892 son roman El Conspirador. Autobiografía de un hombre público. Novela político-social qui met en fiction les mémoires du héros-narrateur Jorge Bello, conçu comme le prototype du conspirateur militaire et politique. Depuis le point de vue narratif de l'introspection qu'offre le récit à la première personne du singulier, ce personnage livre finalement au lecteur un "témoignage » à valeur collective sur la corruption de la politique péruvienne. La romancière développe l'idée qu'on ne naît pas caudillo mais qu'on le devient et invite le lecteur à s'interroger sur les conséquences d'un imaginaire national fondé sur un type de masculinité agressive. Ainsi, cet article propose d'analyser et de définir le modèle alternatif de masculinité suggéré dans $E l$ Conspirador.

The War of the Pacific (1879-1883) presented a major conflict to Peru, impacting the way in which writers conceived the literature and the nation. During this post-war period, the caudillos succeed one another on the Presidential seat. In the discourse of Peruvian intellectuals, the figure of the vindictive soldier becomes an emblem of ideal masculinity. In this contentious context in 1982, the Peruvian writer Mercedes Cabello de Carbonera (1842-1909) publish her novel El Conspirador. Autobiografía de un hombre público where she fictionalizes the memoirs of the hero-Narrator Jorge Bello, designed as a prototype of the military and political conspirator. From the narrative perspective of introspection provided in the story with the first person singular, this character actually delivers the reader a "testimony" of collective value on the Peruvian political corruption. The novelist introduces the idea that we not born a caudillo, but we become one, and invites the reader to ask oneself about the consequences of a national imagination based on such an aggressive type of masculinity. Therefore, this article proposes to analyze and to define the alternative model of masculinity suggested in El Conspirador.

\section{INDEX}

Mots-clés : masculinité, masculinité hégémonique, Pérou, littérature péruvienne, vingtième siècle, fiction, nation, Cabello de Carbonera (Mercedes)

Keywords : masculinity, hegemonic masculinity, Peru, Peruvian literature, nineteenth century, fiction, nation, Cabello de Carbonera (Mercedes) 
AUTEUR

\section{SARAH PORCHERON}

Université de Poitiers, CRLA-Archivos 